\title{
Paradigm Debates in Education: Understanding Their Strengths and Weakness
}

\author{
Yajie Wang ${ }^{1}$ \\ ${ }^{1}$ Moray House School of Education and Sport, The University of Edinburgh, Edinburgh, UK \\ *Corresponding author.Email: S1976328@ed.ac.uk
}

\begin{abstract}
A position often reflects a view of what reality is and how we understand it. It is seen as a discussion of philosophical underpinnings when social researchers clarify their methodologies. However, relating methodologies to the theoretical assumptions often bewilders social researchers, educational researchers particularly (Crotty, 1998). The study contrasts ontological and epistemological positions from the perspectives of positivism and interpretivism and evaluate positivist criteria in educational research. It indicates that a critical awareness of current debates concerning the purposes and interpretation of educational research requires further research.
\end{abstract}

\section{Keywords: Positivism; Interpretivism; Mixed-method; Education}

\section{INTRODUCTION}

A position often reflects a view of what reality is and how we understand it. It is seen as a discussion of philosophical underpinnings when social researchers clarify their methodologies. However, relating methodologies to the theoretical assumptions often bewilders social researchers, educational researchers particularly (Crotty, 1998).

In this paper, I begin with some attempts to contrast ontological and epistemological positions from the perspectives of positivism and interpretivism, then I will critically examine the role of positivism within recent research debates, and finally evaluate positivist criteria in educational research. The paper aims to demonstrate critical awareness of current debates concerning the purposes and interpretation of educational research; evaluate strengths and weaknesses of different research paradigms and philosophies with reference to education.

\section{CONTRASTING POSITIVISMM AND INTERPRETIVISM}

Ontology has been defined as the assumptions and beliefs we hold about reality (Biesta, 2010). Positivists and interpretivists hold contrasting views in ontology. More specifically, the contrast is drawn between independent reality and dependent external reality; one single reality or multiple realities.

Naïve realism, also called "direct realism" (Fish, 2010), is popular in positivism, and claims that there is one single reality and the reality is "out there" (Guba \& Lincoln, 1989), exists independently of being perceived (Phillips, 1987) and these realities can be perceived by human in a valid way. However, interpretivists contend strong or weak relativism. The former describes that realities exist dependently in our consciousness, while the latter recognizes objective reality, and that we can make constructed world based on the objective reality. In brief, interpretivists believe the reality can be perceived by individuals, rather than existing independently of our consciousness.

Additionally, proponents of positivism maintain that it is possible to find a universal law as a knowledge base. By contrast, interpretivists argue that people communicate by negotiating their particular world of ideas, with which people could continuously come to new consensus and create a different set of meaning and classification. Thus, interpretivists advocate multiple realities, since people could conceive and conceptualize these new agreements (Pring, 2000).

Epistemology refers to the nature of knowledge, talking about what we do know and what we can know (Allison \& Pomeroy, 2000). To positivists and interpretivists, they hold contrasting views toward epistemology. The contrast is drawn between whether knowledge can be measured or knowledge can be interpreted; looking for verification of hypotheses or interpreting individual cases in contexts; whether value and fact should be fundamentally divided or not. In other words, the main differences between positivism and interpretivism lie in how we may perceive about knowledge, what each claim about appropriate knowledge gained from respective study and the criteria of assessing knowledge.

Above all, positivists advocate objectivism, claiming knowledge exists independently of our consciousness and experience. Therefore, these meaningful "things" are considered as "objective truth and meaning" (Crotty, 1998), which could be measured and attained by scientific research (generally by numerical function). On the contrary, supporters of interpretivism are in favor of subjectivism or constructivism, so they believe meaning (knowledge) should be constructed or imposed by something. That is to say, the possible epistemological stances of interpretivism refer to symbolic interactionism, implying that the making 
of meaning is a subjective or constructive act independent of the object.

Secondly, for positivists, they suppose that knowledge shares common logical principles, in which human qualities are imbued within scientific understanding. Thus, social science should emulate the tradition of natural science, committing to test hypotheses and providing generalization by experimentation (Coe, 2012). Inversely, interpretivists do not think human behaviors are governed by general laws or can be manipulated in experimental setting. Instead, they regard human beings as being interactive and active in contexts. As Coe (2012) elaborated, human beings can construct and bring situated meaning freely. Moreover, it is neither desirable nor possible to predict certain generalization in determining human behaviors or attitudes since contextualized interactions for human beings are at a high level of complexity (Merriam \& Tisdell, 2015).

Furthermore, for positivists, there is a fundamental distinction between "things material" and "things human" (Hughes \& Sharrock, 2016). In this regard, facts are associated with the world of static, fixed matter, while value is about knowledge in the realm of mind. Therefore, as argued by Hughes and Sharrock (2016), it is evident that the human and material world (value and facts) comprised distinct orders of phenomena. In the study within the positivist paradigm, researchers need to take an objective viewpoint, aiming to establish some "facts" or general laws to clarify human behaviours. Some interpretivists deny the view, insisting that there seems to be no "objective" observer at the beginning, since their positions are affected by prior assumptions. Accordingly, it is not necessary to make a distinction between fact and value since human values are dependent on social phenomena, rather than staying neutral. To this extent, studies using the interpretivist position could describe human values, but cannot assess the ultimate truth

\section{CRITICAL EXAMINATION OF POSITIVISM WITHIN RECENT RESEARCH DEBATE}

Auguste Comtè (1798-1857), a French philosopher and sociologist, is the representative figure of positivism (Howell, 2013), who in his book In a General View of Positivism (1844/1856) divided social development into three stages (Bourdeau, 2008). The origin of Comtè's positivist argument was derived from empiricism within European philosophy since the $17^{\text {th }}$ century. He inherited some of the empiricist tradition from Berkeley (1685-1753) and Hume (1711-1776), who claimed that knowledge has its limits, even as knowledge of the inner mental life of human beings is within scientific understanding. With the effects of enlightenment on empiricism, Comtè coined positivism in 1830s. He held the view that the same principles from natural sciences could be emulated in building social science and achieving positive science of society (Howell, 2013). The principle of positivism is that we can gain verified knowledge through scientific methods, like experimental research.

As Bailey and Eastman (1994) mentioned, the emergence of positivism is the result of specific societal conditions in Europe. The great achievement of Industrial Revolution triggered individual autonomy and contributed to the emergence of a middle class - a novel socio-economic group. As the church was no longer an authority for addressing social problems, the new middle classes began to find other sources of knowledge to guide their beliefs. Here came positivism, underlying natural science methods, approved to bring material and medical benefits to people. As a result, people showed strong enthusiasm for the extension of positivism from natural sciences such as chemistry and biology to social phenomena, implying that human matters were amenable and controllable by scientific inquiry (Mandelbaum, 1971). As such, positivist approaches applied in the social world had been privileged as the dominate epistemology until the late 19th (Gale, 2019).

However, during early $20^{\text {th }}$ century, a growing number of voices persisted in claiming that applying the "scientific method" was insufficient to an understanding of science (Laudan, 1996), and many other research paradigms like interpretivism and the critical tradition flourished in this period (Gage, 1989). These writers defended their arguments through different responses toward social science (Bevir \& Rhodes, 2002), among which was included qualitative and quantitative research debate. The German sociologist Max Weber (1864-1920) won some support, since he combined methodology from both positivism and anti-positivism (Chowdhury, 2014), arguing that social researchers not only need to interpret kulturwissenschaftem (science of nature) (Gale, 2019), but should also seek to conduct cause-effect analysis. However, some logical positivists attacked this view. Roth (1987) took some of Quine's position and proposed "Unity of method assumption". He took for granted that social science and natural science should apply the same method, because if social science could not follow "scientific method", it could not be qualified as science (Hughes \& Sharrock, 2016).

An essential production of this conflict between paradigms is mixed methods research (Bryman, 2008). Proponents of mixed methods claim that it is possible to mix within quantitative research and qualitative research. Recently, pragmatism, a paradigm which ignores methodical differences and attempts to find answers with the most appropriate method, gained popularity in the field. As Greene (1989) emphasized, practitioners of pragmatism have been enthusiastic in applying mixed methods.

It is unsurprising that education and policy researchers are interested in conducting mixed methods research (Becker \& Bryman, 2004). For educational policy-makers, they regard quantitative methods as useful in advising and making change (Howell, 2013). In a traditional framework, educational policy-makers often seek teaching and learning approaches that are objective, effective, measurable and can apply numerical methods (Gage, 1989), which coincides with positivism's quantitative assumptions and approaches. 
They dislike interpretive approaches, concerning smallscale samples. Their aim is to manipulate grand scale samples and identify certain effects on the outcome (Bechhofer \& Paterson, 2012). But in the recent years, policy makers find that while a quantitative approach provide effective strategies, there are still limitations (Green, 2017), as they should go beyond the top-down strategies, and involve themselves in identifying quality criteria and individual differences in contexts.

In this regard, the debate of quantitative-qualitative distinction in policy-making might be ending. Still, as Hammersley (1989) warned, we need be cautious to reach conclusions, since there have been other paradigm debates in addition to the quantitative-qualitative debate.

\section{THE EVALUATION OF POSITIVISM}

The quality of research has to be judged by its own criteria. Every paradigm has its own criteria terms. Reliability, internal validity and generalizability are three criteria employed by positivists (Shenton, 2004) and the three criteria will be evaluated in the section.

Reliability is associated with repeatable results (Geoff \& Judy, 2011). It is about the extent to which the results remain the same over time and space, the stability of results over time. Considering simplified measurement and consistent results, quantitative researchers will use the criterion to conduct social surveys and internet polling with questionnaire sampling (Geoff \& Judy, 2011), aiming to identify the tendency of random variables and its general pattern. Moreover, as Geoff and Judy argued, quantitative research focuses on controlling data and standardized data, thus researchers can easily find ways to check reliability. For qualitative researchers, they might prefer dependability instead of using reliability (Shenton, 2004), concerning operational detail of data gathering and reflective appraisal of the project.

However, there might be problematic issues in checking reliability if we use "unreliable" instruments (Maxwell, 1992). For positivist investigators, the objectives are random people, so the theme of questionnaire could possibly sensitize them, and hence influence their responses in test-retest. Consequently, the accuracy and consistency of the result will be reduced.

Internal validity in positivist work deals with a study's own logic (Geoff \& Judy, 2011), and its result should be defensible. According to Joppe (2000), internal validity determines how truthful the study results are and whether the evidence measures the reality. This definition of internal validity is within the quantitative research tradition, where researchers attempt to distance themselves from study process, trying to establish the hypothesis at the initial stage and find cause and effect laws through analyzing gathered data. Methods frequently used in positivist study are random sampling and statistical tests and procedures (Maxwell, 1992). These approaches enable quantitative researchers to claim validity for larger populations and similar situations, rather than particular groups.
However, some critiques about internal validity lie in the initial established causality (Winter, 2000). Critics emphasis the internal logic form "A, then B" cannot logically be entirely proved of verified, instead, they can be falsified by the form "A is not followed by B" (The philosophy of social research). In other words, for quantitative researcher, the initial causality for tests could be invalid, failing to use inductive reasoning to reach general laws.

Generalizability, also called external validity, is concerned with whether the finding of research can be applied to wider situations and populations (Shenton, 2004). This criterion finds its root in positivist tradition. Maxwell (1992) notes it is common for validity tests in quantitative research to generate findings applicable to larger populations and situations. In natural science like mathematical biology, it is ideal to provide products of averaging instead of description (Pearson, 1911). In social science, quantitative researchers attempt to deal with external validity by conducting observation and empirical methods like numerical analysis and "experiment". This means these researchers strictly define the phenomena into measurable categories, which can be used in a wide range. The generalizability of quantitative study is suitable for some educational policymakers (Pring, 2000), who are finding the explicit strategies in contributing to standard education.

Nevertheless, taking generalizability as a criterion also raises questions of ineffective controls in empirical study as well as damaged accuracy. On the one hand, it is almost impossible to set up experimental conditions for social researchers (Hughes \& Sharrock, 2016), since researchers' preference of selecting and using samples, and failure in isolating other factors from confounding variables, will pollute generalization. On the other hand, the generalization in itself may be invalid (Winter, 2000). Since the generalizable argument is produced from an averaging condition, it may fail to describe a single phenomenon with accuracy.

\section{CONCLUSION}

In conclusion, although the dominance of positivist tradition was initially challenged by interpretivism, and since the $20^{\text {th }}$ century by pragmatism with mixed method research, it is noted that positivism continues to be inevitable as a way to know the world. Accordingly, we are supposed to define positivist position in recent research debates; connect this kind of research with the most appropriate criteria, and find reliable criteria to judge positivist research.

\section{REFERENCES}

[1] Allison, P. \& Pomeroy, E.. How Shall We "Know?" Epistemological Concerns in Research in Experiential Education. Journal of Experiential Education, 2000, pp.91-98. DOI= 
https://doi.org/10.1177/105382590002300207

[2] Bailey, J. R., \& Eastman, W. N. Positivism and the promise of the social sciences. Theory \& Psychology, 1994, pp. 505-524. DOI= https://doiorg.ezproxy.is.ed.ac.uk/10.1177/0959354394044003

[3] Bechhofer, F., \& Paterson, L. Principles of research design in the social sciences. Routledge, 2012.

[4] Becker, S., \& Bryman, A. Qualitative research, 2004.

[5] Bevir, M., \& Rhodes, R. A. Interpretive theory, 2002

[6] Biesta, G. Why “what works" won’t work: Evidencebased practice and the democratic deficit in educational research. Educational theory, 2007, pp.1-22.

[7] Bourdeau, M. Auguste comte, 2008.

[8] Bryman, A. The end of the paradigm wars. The

SAGE handbook of social research methods, 2008, pp.13-25.

[9] Chowdhury, M. F. Interpretivism in aiding our understanding of the contemporary social world. Open Journal of Philosophy, 2014, pp. 432. DOI=

\subsection{6/ojpp. 2014.43047}

[10] Coe, R. J. Conducting your research. Research methods and methodologies in education, 2012, pp. 4152 .

[11] Crotty, M. The foundations of social research: Meaning and perspective in the research process. Sage, 1998.

[12] Fish, W. Philosophy of perception: A contemporary introduction. Routledge, 2010.

[13] Gage, N. L. The paradigm wars and their aftermath a "historical" sketch of research on teaching since 1989. Educational researcher, 1989, pp. 4-10. DOI=https://doi org.ezproxy.is.ed.ac.uk/10.3102/0013189X018007004

[14] Gale.Macleod. "Paradigm Wars": A lot of fuss about nothing [Powerpoint slides]. Retrieved from https://www.learn.ed.ac.uk/webapps/blackboard/execut e/content/file?cmd=view\&content_id=_4258026_1\&co urse_id=_71635_1\&framesetWrapped=true, 2019

[15] Greene, J. C., Caracelli, V. J., \& Graham, W. F. 1989. Toward a conceptual framework for mixedmethod evaluation designs. Educational evaluation and policy analysis, 1989 , pp. $255-274$. DOI=https://doiorg.ezproxy.is.ed.ac.uk/10.3102/01623737011003255

[16] Green, T. L. From positivism to critical theory:

School-community relations toward community equity literacy. International Journal of Qualitative Studies in Education, 2016, pp. 370-387. DOI=

\section{$10.1080 / 09518398.2016 .1253892$}

[17] Guba, E. G. and Lincoln, V. S. Fourth Generation Evaluation, London, Sage, 1989.

[18] Hammersley, M. 2018. Routledge Revivals: The Dilemma of Qualitative Method: Herbert Blumer and the Chicago Tradition. Routledge, 1989.

[19] Howell, K. E. Empiricism, positivism and postpositivism. An introduction to the philosophy of methodology, 2013.

[20] Hughes, J. A., \& Sharrock, W. W. The philosophyof social research. Routledge, 2016.

[21] Laudan, L. Beyond positivism and relativism: Theory, method, and evidence, 1996.

[22] Joppe, M. The Research Process, 2000

[23] Mandelbaum, D. On decoding of Reed-Solomon codes. IEEE Transactions on Information Theory, 1971, pp. $707-712 . \mathrm{DOI}=$

10.1109/tit.1971.1054724

[24] Mandelbaum, M.. History, Man, \& Reason.

Maxwell, J. 1992. Understanding and validity in qualitative research. Harvard educational review, 1992, pp. 279-301. DOI=

\subsection{3/haer.62.3.8323320856251826}

[25] Merriam, S. B., \& Tisdell, E. J. Qualitative research: A guide to design and implementation. John Wiley \& Sons, 2015.

[26] Payne, G., \& Payne, J. Key concepts in social research. Sage, 2004.

[27] Pearson, K. On the probability that two independent distributions of frequency are really samples from the same population. Biometrika, 8, 1/2, 1911, pp. 250-254. $\mathrm{DOI}=$

$10.2307 / 2331978$ 
[28] Phillips, D. C.. Philosophy, science and social inquiry: Contemporary methodological controversies in social science and related applied fields of research. Pergamon Press, 1987.

[29] Pring, R. The 'false dualism'of educational research. Journal of Philosophy of Education, 2000, pp. 247-260. DOI=

$10.1111 / 1467-9752.00171$

[30] Shenton, A. K. Strategies for ensuring trustworthiness in qualitative research projects. Education for information, 2004, pp. 63-75. DOI=

10.3233/EFI-2004-22201

[31] Winter, G. A comparative discussion of the notion of validity in qualitative and quantitative research. The qualitative report, 2000, pp. 1-14. 